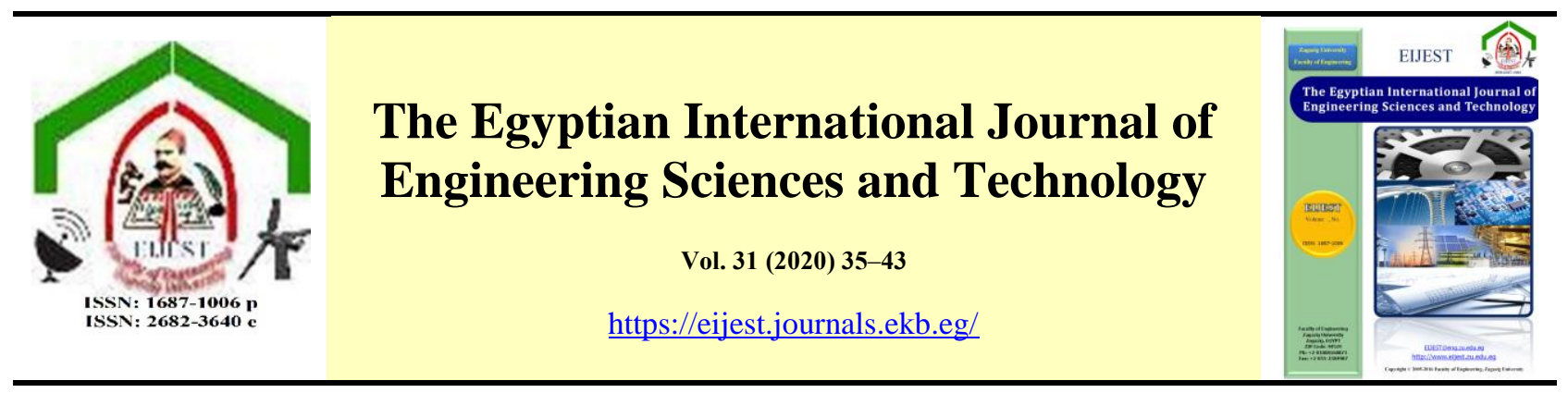

\title{
Strength Properties of Nano and Micro Silica Mortar
}

\author{
Louay A. Aboul-Nour ${ }^{a^{*}}$, Heba A. Mohamed ${ }^{\mathrm{a}}$, Mona Teama ${ }^{\mathrm{b}}$ \\ ${ }^{a}$ Associate professor Structural Eng. Dept., Faculty of Eng., Zagazig University, Zagazig 44519, Egypt. \\ ${ }^{b}$ Civil Eng., Structural Eng. Dept., Faculty of Eng., Zagazig University, Zagazig 44519, Egypt
}

\section{ART I CLE INFO}

Keywords:

nano-silica

micro-silica

blended cement mortar

compressive strength

tensile strength

abrasion strength

\begin{abstract}
A B S T R A C T
Nano technology is increasingly being used in concrete industry, and in particular the use of nano silica particles in cementitious materials is becoming more popular to improve concrete properties. This paper deals with studying the influence of replacing a portion of cement with either nano silica NS, micro silica MS, or a combination of both, on the strength properties (compression, tension and abrasion) of the cementitious mortars produced. Micro-silica particles are altered from 0,5 and $10 \%$ while nano-silica particles are altered from $0,0.5$ and $1.0 \%$. The paper reveals the method of mixing nano particles to prevent agglomeration and achieve a homogeneous mix so that the nano particles are well dispersed throughout the mortar matrix. Results indicate that incorporating a combination of both micro and nano particles improve the mechanical properties of the mortar matrix. Where compression improved by approximately $39 \%$ for $10 \%$ micro silica plus $1 \%$ nano silica. Tensile strength also improved by $19 \%$ for $5 \%$ micro silica plus $0.5 \%$ nano silica. While the abrasion resistance showed an exceptional improvement of $92 \%$ for $10 \%$ micro silica plus $1 \%$ nano silica.
\end{abstract}

\section{Introduction}

Nanotechnology is a rapidly growing feature in many fields of science and engineering. It allows for designing materials according to need hence it has great impact and possesses high marketing potential. There is a highly increasing need for research and exploration in implementing nano technology in the field of construction. Recently the last few decades, researchers have applied different nano particle materials to cements and concrete in order to measure and assess the performance of nano particles in the field of building construction [1]. In concrete industry, nano silica is the most broadly used material as a partial replacement for cement in effort to improve concrete performance [2]. The objective of this paper is to study the effect of implementing either nano silica or micro silica or a combination both on the mechanical properties of cement mortars.
Both nano and micro particles have a favorable so where these fine particles reside in the larger interparticle cement voids leading to denser structure. Combined replacement of nano and micro particles of different supplementary cementitious admixtures has been investigated by many researchers [3-5]. Previously, (MS) micro silica is an amorphous noncrystalline polymorph of silicon dioxide $\left(\mathrm{SiO}_{2}\right)$ form of pozzolan. It possesses a high specific surface area that allows for its great pozzolanic activity, where it has been applied to concrete and has improved the mechanical properties of hardened cement mortar [6]. Nowadays, nano silica which is an amorphous silicon dioxide $\left(\mathrm{SiO}_{2}\right)$ core with a hydroxylated surface form of pozzolan. Having an ultra-high specific area which allows for an even better void filling ability, hence improving the cement paste microstructure, favorably enhancing both plastic and hardened characteristics $[7,8]$. On the mortar level, micro and nano silica 
cement mortars are highly superior to traditional cement mortars when mixed and cured under high temperatures [1,9]. Comparing cement mortar of micro silica to those of nano silica indicates that nano silica is more valuable in providing strengthen to the mortar than micro silica [10]. Nano silica particles are much finer than micro silica which further increases the surface area of the reactive powders of the mix but they also result in a rapid decrease in consistency and workability [11]. The effect of nano particles varied according to its method of incorporation in the mix, whether by addition or by replacement. Also, the method of mixing either wet or dry has a noticeable effect on the mechanical properties of concrete [12]. Accordingly, for best results it is recommended to use ultrasonic technology under high temperatures to achieve very effective dispersion of the nano silica particles throughout the mortar matrix. Resulting in better homogeneity of the mix and superior mechanical strength and superb durability resulting in ultra-high strength and performance concrete [13-15]. This experimental investigation aims to determine the influence of micro silica, nano silica or a combination of both (as a partial replacement of cement) on the mechanical properties of the produced mortar.

\section{Experimental Program}

The details descriptions of the materials used through this investigation include; cement, fine aggregate, micro-silica, nano-silica, and chemical admixture (super plasticizer) are presented.

\subsection{Materials properties}

\subsubsection{Cement}

Ordinary Portland Cement (OPC) Type I (CEM I $52.5 \mathrm{~N}$ ) produced by Bani Sweif cement factory is used in this study according to the Egyptian standard specification of Cement (4756-1/2009) [16].

\subsubsection{Fine Aggregates}

All aggregates used in this research are locally available from quarries in the Arab republic of Egypt. The fine aggregate used for all mortars is clean, dry standard sand (passing $0.85 \mathrm{~mm}$ and retaining 0.60 $\mathrm{mm}$ ) which complies with (ASTM C109) [17], (ASTM C190) [18], and (ASTM C418-20) [19]. Other physical properties include the specific gravity of 2.57 , finest modulus of 3.11 , and dry unit weight of $1.78 \mathrm{t} / \mathrm{m}^{3}$.

\subsubsection{Mineral Admixtures (Pozzolans)}

\subsubsection{Micro Silica}

Micro silica used in this research as a mineral admixture is imported from Belgium by Cementrac Cement Company. Physical properties and shape of MS are stated in the data sheet (Table 1 \& Fig. 1).

\subsubsection{Nano Silica}

Nano silica consists of a silicon dioxide with purity $99.8 \%$ is a product of the Nano Science and Technology Institute Kafr El-Sheikh University. Physical properties and shape are stated in the data sheet (Table 1 \& Fig. 1).

Table 1: The physical properties of the used micro silica and nano silica.

\begin{tabular}{lcc}
\hline Property & Micro silica & Nano silica \\
\hline Silicon Oxides & $97 \%$ & $99.8 \%$ \\
\hline $\begin{array}{l}\text { Surface Area } \\
\left(\mathrm{cm}^{2} / \mathrm{gm}\right)\end{array}$ & 170000 & 240000 \\
\hline Particle Size & $\begin{array}{c}1.0 \\
1.0-2.0 \times 10^{-6} \mathrm{~m}\end{array}$ & $\begin{array}{c}-2.0 \mu \mathrm{m} \\
5-20 \times 10^{-9} \mathrm{~m}\end{array}$ \\
\hline Specific Gravity & 2.20 & 2.40 \\
\hline Unit Weight & 345 & 505 \\
$\left(\mathrm{Kg} / \mathrm{m}^{3}\right)$ & Grey & White \\
\hline Color & & \\
\hline
\end{tabular}

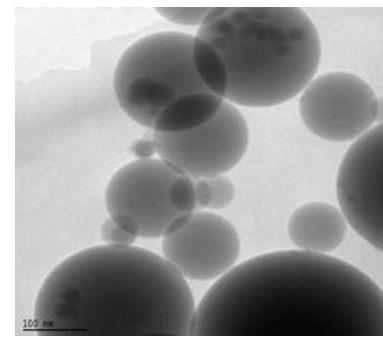

a) Micro Silica Particles

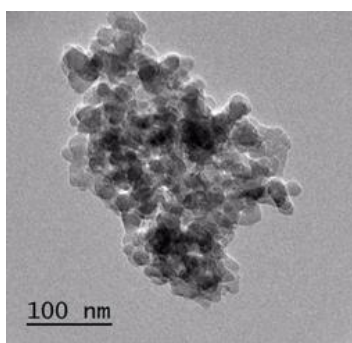

b) Nano Silica Particles
Figure 1. Transmission Electron Microscope TEM Images of Micro and Nano Silica.

\subsubsection{Chemical admixture (Super plasticizer)}

A high range water reducer super plasticizer concrete admixture Sikament-NN is used in this work; it is a third-generation super plasticizer consisting of Naphthalene base Sulphonate which is 
used for producing high and ultra-high strength concretes and mortars. It has a density of $1.185 \mathrm{~kg} / \mathrm{lit}$, a $\mathrm{Ph}$ value of 8 , and it meets the requirements for super plasticizers according to (ASTM C494) [20] Type A \& F and EN 934-2:2001. The used dosage of super plasticizers was maintained constant at $2.5 \%$ by weight of cement for all mixes.

\section{Test Specimens}

Several mixes are investigated altering the percent of replacement of either nano silica or micro silica or a combination of both. Mortar cubes $7 \times 7 \times 7 \mathrm{~cm}$ in dimension are for compression test, mortar briquettes of width $2.54 \mathrm{~cm}$ and depth $2.54 \mathrm{~cm}$ are for tension test, and short cylinders of diameter $3 \mathrm{~cm}$ and height $4 \mathrm{~cm}$ for abrasion test (Fig. 2). The experimental program (Table 2) includes nine mixes that were all designed based on the absolute volume of the constituent materials in a saturated surface dry condition. The mixes include a control mix (M0N0) without any mineral admixture additives. Two other mixes (M5N0 \& M10N0) consist of cement replaced by 5 and 10 percent of micro silica without nano silica. Another two mixes (M0N0.5 \& M0N1.0) consist of cement replaced by 0.5 and 1.0 percent of nano silica without micro silica. These previous mixes illustrate the effect of replacing cement by either micro or nano silica alone without their combined effect. Another four mixes include different combinations (M5N0.5, M5N1.0, M10N0.5, \& M10N1.0). Where the first (M5N0.5) consist of $5 \%$ micro-silica and $0.5 \%$ nano silica, the second (M5N1.0) consist of 5\% micro-silica and $1.0 \%$ nano silica, the third (M10N0.5) consists of $10 \%$ micro silica and $0.5 \%$ nano-silica, and the fourth (M10N1.0) consists of $10 \%$ micro silica and $1.0 \%$ nano silica. These four mixes illustrate the combined effect of replacing the cement with a combination of both micro and nano silica. The cementitious content of all mixes is maintained constant using a constant dose of $2.5 \%$ high range water reducer (superplasticizer) by weight of cementitious materials along with a fixed 0.4 water/cementitious ratio. Mechanical properties of cement mortars are dependent on many parameter, and according to the previous literature properties are influenced by the water/cement ratio (W/C) [21], aggregate/cement ratio (A/C) [22,23], age [24,3], and admixture dose $[25,26]$.
Table 2: Test program and contents of mixtures

\begin{tabular}{|c|c|c|c|c|}
\hline \multirow{2}{*}{\multicolumn{2}{|c|}{ Binder }} & \multicolumn{3}{|c|}{ Replacement \% of Micro silica } \\
\hline & & $0 \%$ & $5 \%$ & $10 \%$ \\
\hline \multirow{3}{*}{  } & $0 \%$ & \begin{tabular}{c}
\multicolumn{1}{c}{ MON0 } \\
$100 \% \mathrm{OPC}$ \\
$0 \% \mathrm{Ms}$ \\
$+0 \% \mathrm{Ns}$
\end{tabular} & \begin{tabular}{c}
\multicolumn{1}{c}{ M5N0 } \\
$95 \% \mathrm{OPC}$ \\
$5 \% \mathrm{Ms}$ \\
$+0 \% \mathrm{Ns}$
\end{tabular} & $\begin{array}{c}\text { M10N0 } \\
90 \% \mathrm{OPC} \\
10 \% \mathrm{Ms} \\
+0 \% \mathrm{Ns}\end{array}$ \\
\hline & $0.5 \%$ & $\begin{array}{c}\text { M0N0.5 } \\
99.5 \% \text { OPC } \\
0 \% \mathrm{Ms} \\
+0.5 \% \mathrm{Ns}\end{array}$ & $\begin{array}{c}\text { M5N0.5 } \\
94.5 \% \mathrm{OPC} \\
5 \% \mathrm{Ms} \\
+0.5 \% \mathrm{Ns}\end{array}$ & $\begin{array}{l}\text { M10N0.5 } \\
89.5 \% \text { OPC } \\
10 \% \mathrm{Ms} \\
+0.5 \mathrm{Ns}\end{array}$ \\
\hline & $1.0 \%$ & $\begin{array}{c}\text { M0N1.0 } \\
\text { 99\%OPC } \\
0 \% \mathrm{MS} \\
+1.0 \% \mathrm{NS}\end{array}$ & $\begin{array}{c}\text { M5N1.0 } \\
94 \% \mathrm{OPC} \\
5 \% \mathrm{Ms} \\
+1.0 \% \mathrm{Ns}\end{array}$ & $\begin{array}{l}\text { M10N1.0 } \\
89 \% \text { OPC } \\
10 \% \mathrm{Ms} \\
+1.0 \% \mathrm{Ns}\end{array}$ \\
\hline
\end{tabular}

*Compression specimens include $\mathrm{C}$ in their ID.

Tension specimens include $\mathrm{T}$ in their ID.

Abrasion specimens include Ain their ID.

\section{Mixing Procedure}

To get a high strength mortar, water-cement ratio must be minimized. Therefore, special mixing procedure should be carried out to assure that the fine particles are well dispersed through the matrix. Components are mixed using high speed rotation mixing device and mix proportions illustrated in (Table 3).

Table 3: Mix Proportions of Mechanical Properties

\begin{tabular}{|c|c|c|c|}
\hline \multirow{2}{*}{ Test } & \multicolumn{3}{|c|}{ Proportions } \\
\cline { 2 - 4 } & Binder & Sand & W/C \\
\hline $\begin{array}{c}\text { Compression } \\
\text { Strength (ASTM } \\
\text { C109) }\end{array}$ & 1 & 3 & 0.4 \\
\hline $\begin{array}{c}\text { Tensile Strength } \\
\text { (ASTM C190) }\end{array}$ & 1 & 4 & 0.4 \\
\hline $\begin{array}{c}\text { Abrasion Resistance } \\
\text { (ASTM C418) }\end{array}$ & 1 & 3 & 0.4 \\
\hline
\end{tabular}

** HRWR used is $2.5 \%$ of binder content.

\subsection{Mixes without Nano Silica:}

First of all, the fine aggregate, cement, micro silica, are thoroughly mixed in dry state for 2 minutes, after that liquids including water and superplasticizer are added gradually then further mixed for another 3 minutes till a uniform and homogeneous texture is achieved.

The mortar mix is removed from the mixer and placed in previously greased molds to eases the demolding process, then cured by submersion in fresh water until the day of testing. 


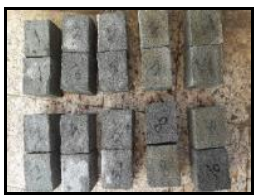

a) Compression cubes

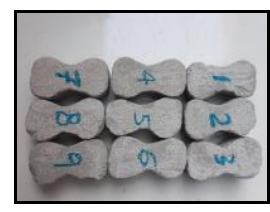

b) Tension briquets

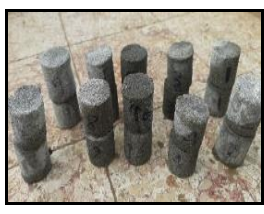

c) Abrasion cylinders
Figure 2. Different Specimens Tested

\subsection{Mixes with Nano Silica:}

Firstly, the fine aggregate, cement, micro silica, are thoroughly mixed in dry state for 2 minutes, then three fourth of the water content is added gradually to the dry mix and further mixed for another minute.

The entire dose of superplasticizer is added to the remaining one fourth amount of water content, which is then poured in the ultrasonic mixing (Fig. 3) device containing the amount of nano silica particles. The ultra-sonic mixing device is turned on and mixing is continued for 10 minutes at a $40^{\circ} \mathrm{C}$ temperature, to achieve the best possible dispersion of nanoparticles in solution and preventing agglomeration.

The nano particle solution is then added to the wet mix of sand, cement and micro silica which is then further mixed for another four minutes. Casting the mortar in the molds and their curing is performed as previously mentioned.

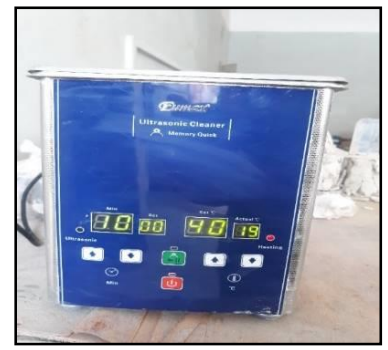

Figure 3. Ultrasonic Device for Mixing Nanoparticles.

\section{Setup and Testing}

\subsection{Compression test}

The compression test (Fig. 4a) is performed and the compression strength is calculated by dividing the maximum test failure load by the cross-section area (subjected to the compression load) of the test specimens.

\subsection{Tension test}

For tension test (Fig. 4b) briquette specimen is inserted between the hooks of machine then is tightened until separation and the tensile strength is calculated by dividing the maximum test failure load by the cross-section area (subjected to the tension load) of the test specimens.

\subsection{Abrasion test}

The short cylinder specimen (Fig. 4c) is placed touching the lever, the lever spin 500 cycle and then for abrasion ratio calculate the difference in weight before and after the test.



a) Compression

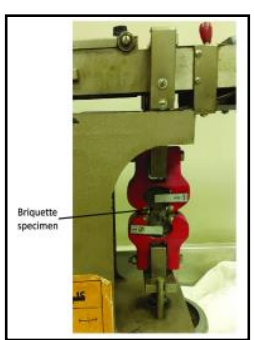

b) Tension

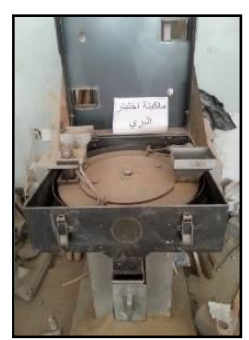

c) Abrasion
Figure 4. Machines used for different tests.

\section{Experimental Results and Discussion}

\subsection{Compressive Strength}

Specimens CM0N0, CM0N0.5, and CM0N1.0 that all possessed $0 \%$ micro silica, with $0,0.5$, and $1.0 \%$ of nano silica respectively. The compressive strength has increased considerably by $14.15 \%$ and $14.92 \%$ from CM0N0 for $0.5 \%$ and $1.0 \%$ nano silica respectively at 28-days (Fig. 5a). Whereas at 56-days compressive strength has increased by $11.61 \%$ and $13.79 \%$ from CMON0 for $0.5 \%$ and $1 \%$ nano silica respectively (Fig. 5b).

Specimens CM0N0, CM5N0, and CM10N0 that all possessed $0 \%$ nano silica, with 0,5 , and $10 \%$ of micro silica respectively. According to the literature the micro particles improve the packing characteristics of the matrix hence have a noticeable effect on the compressive strength. At 28-days there is significant increase in compressive strength by $15.28 \%$ and $20.14 \%$ from CMONO for 5\% and $10 \%$ micro silica respectively, indicating great resistance of the mortar cube (Fig. 5c). Whereas at 56-days compressive strength has increased by $14.88 \%$ and $17.40 \%$ from CMON0 for 5\% MS and 10\%MS respectively (Fig. 5d). Artificial supplementary cementitious materials such as micro silica, nanosilica, fly ash and metakaolin have been widely used for different purposes. Literature has shown that 
compressive strength increases by adding mineral admixtures to mortar due to its pozzolanic reactions and chemical composition [27,28]. A comparison between the compressive strength for mixes CM5N0, CM5N0.5 and CM5N1.0 at 28 and 56-days respectively. The micro silica content was $5 \%$ and the content of nano silica was $0,0.5$ and $1.0 \%$ respectively. The data in figures clearly show a remarkable increase in compressive strength at both 28 and 56-days due to a marginal implementation of nano silica. The compressive strength at 28-days increased by 7.45 and $10.02 \%$ from CM5N0 for nano silica contents 0.5 and $1.0 \%$ respectively (Fig. 5a). While the compressive strength at 56-days increased by 4.42 and $10.07 \%$ from CM5N0 for Nano silica contents 0.5 and $1.0 \%$ respectively (Fig. 5 b). Similar results are recorded for the specimens CM10N0, CM10N0.5 and CM10N1.0 possessing the same aggregate composition, w/c ratio, micro silica content, and curing conditions. The data in figures clearly show an improvement in the compressive strength due to addition of Nano silica by 0.5 and $1.0 \%$. Where, the compressive strength at 28 -days increased by 13.02 and $15.52 \%$ from CM10N0 (Fig. 5a). While the compressive strength at 56-days increased by 14.22 and $16.01 \%$ from CM10N0 for CM10N0.5 and CM10N1.0 respectively (Fig. 5b).

This improvement can be referred to the filler action of nano silica and micro silica which have a large surface area which improves the chemical reaction due to the pozzolanic activity. Hence additional Calcium Silicate Hydrates C-S-H is formed generating more gel due to hydration resulting in increased strength [29-35].



a) Effect of Nano Silica at 28-days

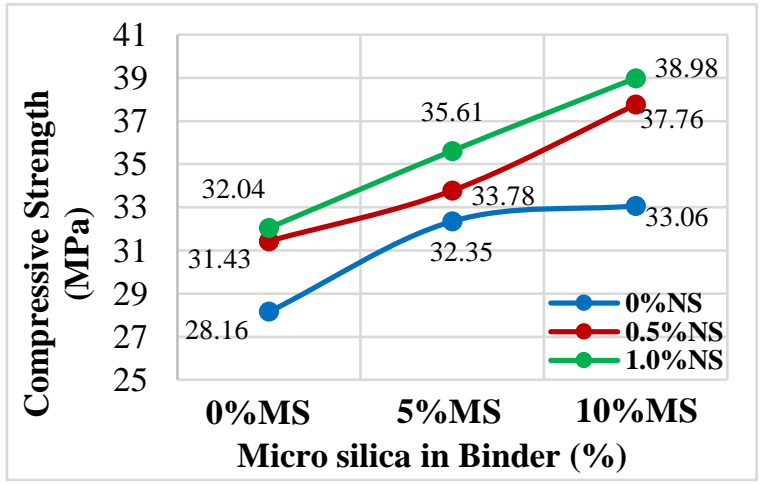

b) Effect of Nano Silica at 56-days

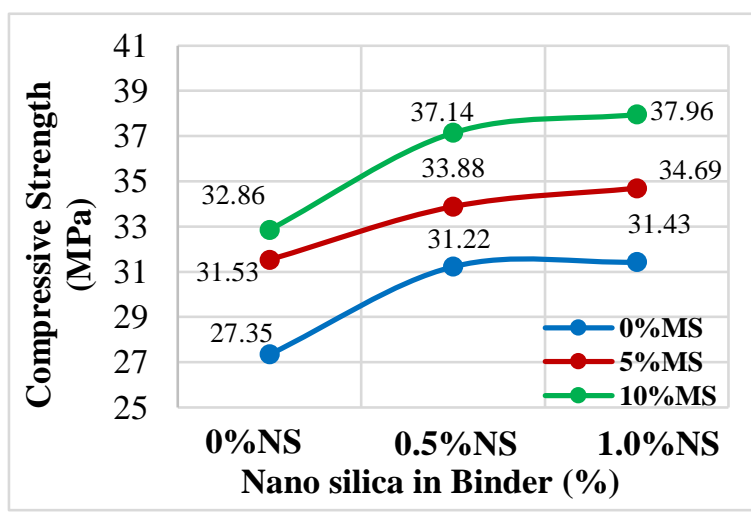

c) Effect of Micro Silica at 28-days

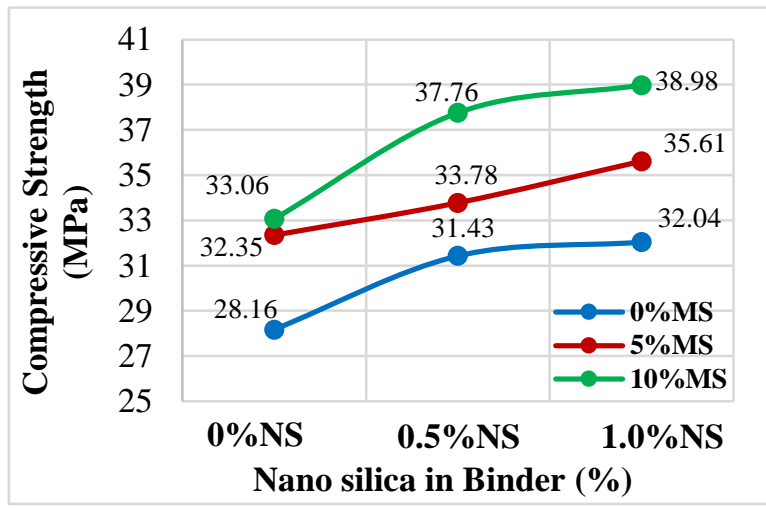

d) Effect of Micro Silica at 56-days

Figure 5. Effect of MS content, NS content, and combination of them together on the Compressive strength at 28 and 56-days.

\subsection{Tensile Strength}

In this section the effect of the replacement of cement with NS, MS, and a combination of both is studied for the tensile strength at 28 and 56 days. The effect of replacing cement with NS only is shown by specimens TMONO, TM0N0.5, and TM0N1.0. It's noticed that the tensile strength of TM0N0.5 is higher 
than TM0N0 by $10.53 \%$ and $10.23 \%$ at 28 and 56days respectively. Similarly, the tensile strength of TM0N1.0 is higher than TM0N0 by $7.11 \%$ and $6.65 \%$ at 28 and 56-days respectively (Fig. 6a\&6b).

Studying tensile strength at 28 and 56-days and the effect of replacing cement with MS only is illustrated by specimens TM0N0, TM5N0, and TM10N0. The result reveal that the tensile strength of TM5N0 is higher than the control specimen TM0N0 by $12.11 \%$ and $11.76 \%$ at 28 and 56-days, respectively and for specimen TM10N0 the tensile strength increased by $3.42 \%$ and $3.07 \%$ for 28 and 56-days respectively (Fig. 6c\&6d). In using a combination of both MS and NS in the same mix with a 5\% MS content which involve specimens TM5N0, TM5N0.5 and TM5N1.0 it is noticed that by increasing NS content, the tensile strength of specimen TM5N0.5 increases by $7.51 \%$ and $6.41 \%$ from TM5N0 at 28 and 56 days respectively and for specimen TM5N1.0 by $4.93 \%$ and $5.03 \%$ from TM5N0 at 28 and 56-days respectively (Fig. 6a\&6b).

Similarly, specimens TM10N0, TM10N0.5 and TM10N1.0 having a 10\% MS content and variable NS ratios exhibited an increase in tensile strength for specimen TM10N0.5 by $11.96 \%$ and $11.91 \%$ from TM10N0 at 28 and 56-days respectively and for specimen TM10N1.0 by $9.41 \%$ and $8.68 \%$ from TM10N0 at 28 and 56-days respectively (Fig. $6 a \& 6 b)$.

This clear enhancement in tensile strength of concrete, at 28 and 56-days has been noted by other researchers [36, 37], where the addition of mineral admixtures results in an increase in overall concrete strengths including compressive, split-tensile and flexure [36].

It is not necessary that when compressive strength increases tensile strength also increases.

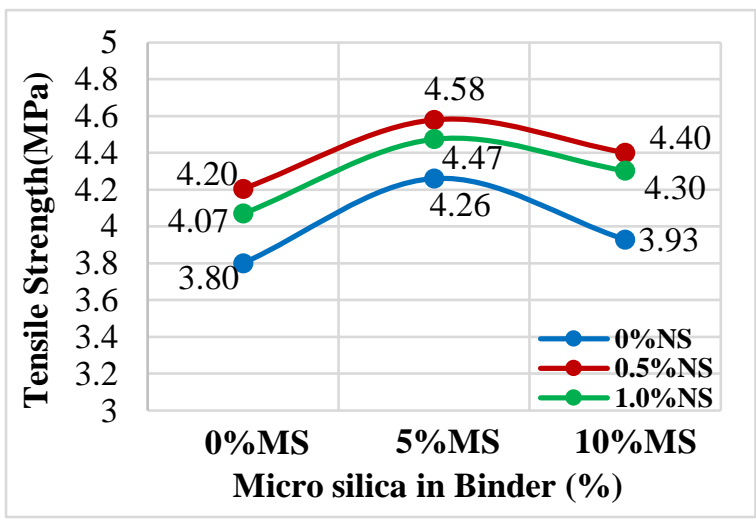

a) Effect of Nano Silica at 28-days

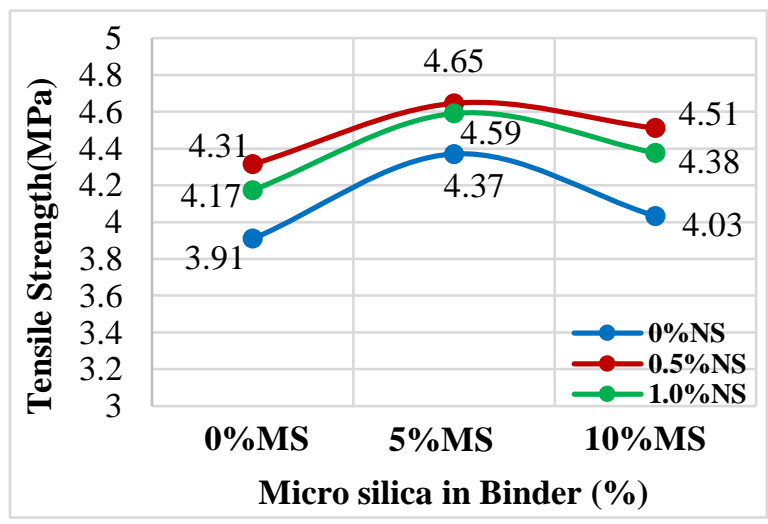

b) Effect of Nano Silica at 56-days

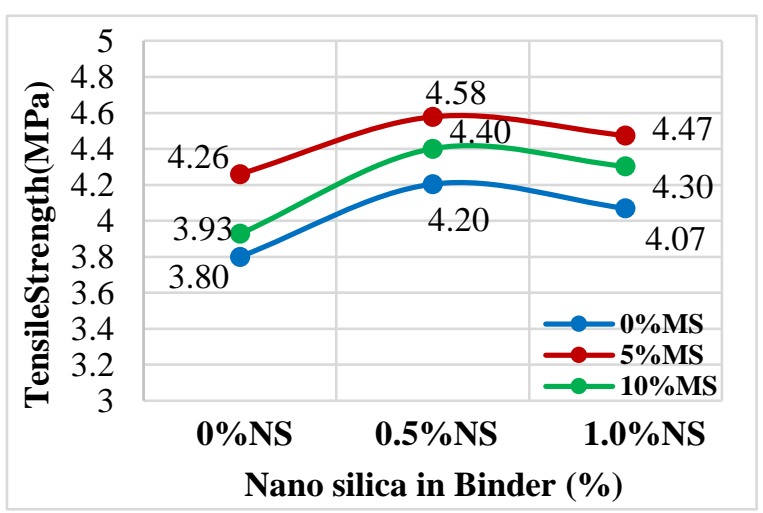

c) Effect of Micro Silica at 28-days



d) Effect of Micro Silica at 56-days

Figure 6. Effect of NS, MS, and combination on the Tensile strength at 28 and 56-days.

\subsection{Abrasion Strength}

This part includes determining the effect of different replacement ratios of nano and micro materials on the abrasion ratio of the short cylinder specimens subjected to abrasion. Firstly, replacing cement with NS only for specimens AM0N0, AM0N0.5, and AM0N1.0. The figures clearly show great reduction in the abrasion ratio, where the 
abrasion ratio of specimens AM0N0.5 and AM0N1.0 decreased by $11.12 \%$ and $15.36 \%$ from AM0N0 at 28 days and $10.47 \%$ and $15.55 \%$ from AMON0 at 56days (Fig. 7a\&7b). For the effect of micro silica alone for specimens AM0N0, AM5N0 and AM10N0 at 28 and 56-days, result show a remarkable drop in abrasion for AM5N0 and AM10N0 by $22.02 \%$ and $30.0 \%$ from AMONO at 28-days and $30.8 \%$ and $34.57 \%$ from AMON0 at 56-days (Fig. 7c\&7d). Regarding mixing a combination of MS and NS with a $5 \%$ constant MS content and a variable NS ratio is depicted by specimens AM5N0, AM5N0.5, and AM5N1.0. Specimens AM5N0.5 and AM5N1.0 have exhibited a high reduction in abrasion ratio by $22.03 \%$ and $37.13 \%$ from AM5N0 at 28-days and $14.68 \%$ and $19.62 \%$ from AM5N0 at 56-days (Fig. $7 \mathrm{a} \& 7 \mathrm{~b}$ ). Similarly, for a combination of MS and NS with a $10 \%$ constant MS content and a variable NS ratio is shown by specimens AM10N0, AM10N0.5, and AM10N1.0. Specimens AM10N0.5, and AM10N1.0 have also exhibited an even better performance where the abrasion ratio has greatly decrease by $43.65 \%$ and $47.73 \%$ from AM10NO at 28-days and $29.26 \%$ and $40.46 \%$ from AM10NO at 56-days (Fig. 7a\&7b). Cement mortar with NS and MS give higher abrasion resistance than that of control cement mortar and cement mortar with MS or NS only. The reasons may come from the fact that cement mortar with NS has a less porous structure and results in a denser and more compact texture [38]. Similar results are found in the works of Riahi and Nazari [39], Nazari and Raihi [40], Soleymani [41], and $\mathrm{Li}$ [42] who studied the abrasion resistance of concrete modified with NS. These works suggested that the abrasion resistance increased with the addition of NS for all ages of cement mortar.

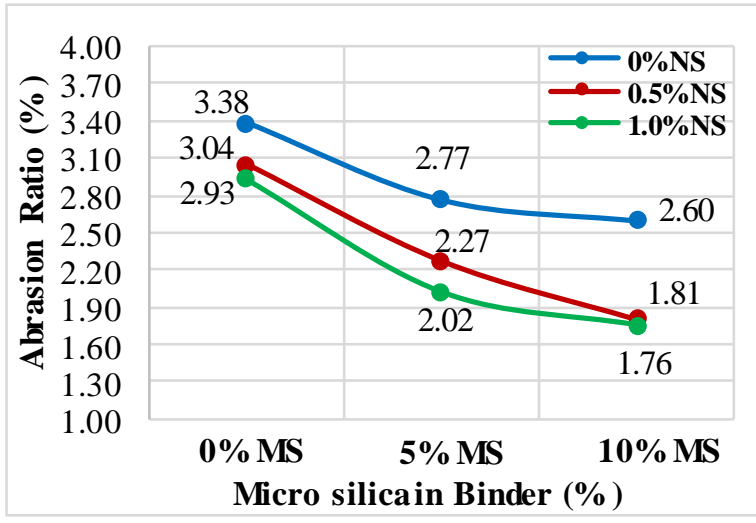

a) Effect of Nano Silica at 28-days

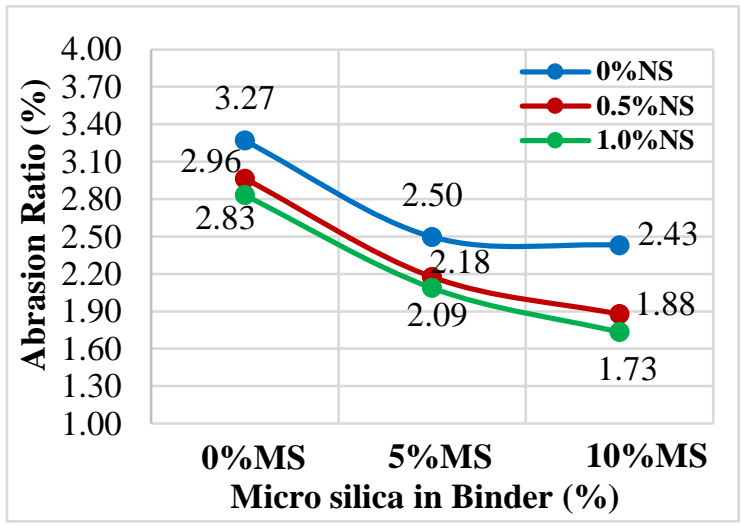

b) Effect of Nano Silica at 56-days

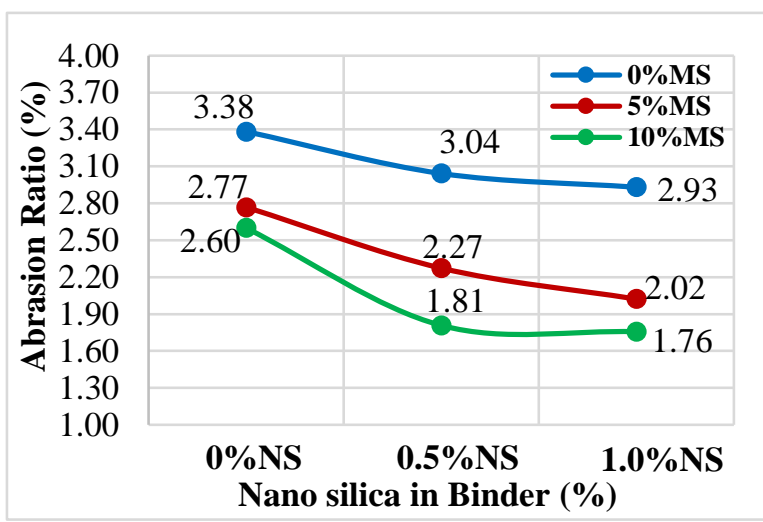

c) Effect of Micro Silica at 28-days

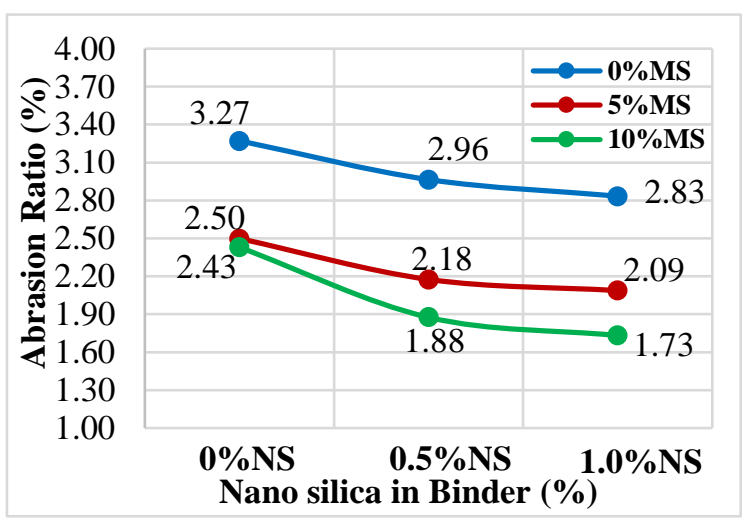

d) Effect of Micro Silica at 56-days

Figure 7. Effect of NS, MS, and combination on the Abrasion ratio at 28 and 56-days.

\section{Conclusions}

In this research, the experimental program was carried out to investigate the effect of using microsilica as well as nano-silica as a mineral admixture to be used as a partial replacement of cement. Based on the obtained results, the following main conclusions can be drawn: 
- Addition of $5 \%$ and $10 \%$ micro silica lead to significant increase in both compressive and tensile strengths and a distinguished decrease in the abrasion ratio at 28 and 56-days.

- The compressive strength at 28-days increased by about $15.28 \%$ and $20.14 \%$ and at 56 -days increased by $14.88 \%$ and $17.40 \%$. Also, the tensile strength increased by $12.11 \%$ and $3.42 \%$ at 28 -days and $11.76 \%$ and $3.07 \%$ at 56 -days. Whereas the abrasion ratio has improved when $5 \%$ and $10 \%$ MS was used where the abrasion ratio was reduced by $22.02 \%$ and $30.0 \%$ at 28 days and $30.80 \%$ and $34.57 \%$ at 56 -days.

- The results in this research show an improvement in the mechanical properties due to replacement by Nano silica by $0.5 \%$ and $1.0 \%$. Where, the compressive strength at 28-days increased by about $14.15 \%$ and $14.92 \%$ and at 56-days increased by $11.61 \%$ and $13.79 \%$. Also, the tensile strength increased by $10.53 \%$ and $7.11 \%$ at 28 -days and $10.23 \%$ and $6.65 \%$ at 56 -days. Whereas the abrasion ratio has improved when $0.5 \%$ and $1 \%$ NS was used where the abrasion ratio was reduced by $11.12 \%$ and $15.36 \%$ at 28 days and $10.47 \%$ and $15.55 \%$ at 56 -days.

- For mixes with combination of NS and MS, the increase of Nano silica content from $0.5 \%$ to $1.0 \%$ caused an increase in the compressive, tensile strength, and substantial decrease in abrasion ratio.

- The results in this investigation show a remarkable improvement in mechanical properties at 28 and 56-days. The highest improvement in compression results occurred in specimen CM10N1.0 which contains $10 \%$ MS and $1.0 \% \mathrm{NS}$ where an improvement of $38.79 \%$ and $38.42 \%$ from control sample (CMON0) is recorded at 28 and 56 days respectively. The highest improvement in tension results occurred in specimen TM5N0.5 which contains 5\% MS and $0.5 \% \mathrm{NS}$ where an improvement of $20.53 \%$ and $18.93 \%$ from control sample (TM0N0) is recorded at 28 and 56 days respectively. The best abrasion resistance was exhibited by specimen AM10N1.0 which contains $10 \% \mathrm{MS}$ and $1.0 \% \mathrm{NS}$ where the abrasion ratio decreased by $92.05 \%$ and $89.02 \%$ from control sample (AMON0) at 28 and 56 days respectively.

- It has been noticed from the results, that for compression improves with the addition of both nano and micro silica although an indefinite increase in either micro or nano silica is uneconomical. On the other hand, small amounts of micro and nano silica have proved to be more beneficial in improving the tension. It is worth noting that presence of nano and micro silica greatly enhances the abrasion resistance which is due to the better packing of the matrix.

\section{References}

[1] A.M. Said, M.S. Zeidan, M.T. Bassuoni, and Y. Tian, "Properties of concrete incorporating nano silica", Construction and Building Materials Vol.36, pp. 838-844, 2012.

[2] P.J. Ramadhansyah, M.Y. Mohd Ibrahim, Mohd Rosli Hainin, M.W.M. Naqiuddin, and M.H. Wan Ibrahim, "Porous Concrete Pavement Containing Nano-silica": Pre-Review, Advanced Materials Research Vol. 911, pp. 454-458, 2014.

[3] A. Kooshkaki, and H. Eskandari-Naddaf, "Effect of porosity on predicting compressive and flexural strength of cement mortar containing micro and nano silica by multi-objective ANN modeling", Constr. Build. Mater. Vol. 212, pp. 176191, 2019.

[4] L.G. Li, J.Y. Zheng, J. Zhu, and A.K.H. Kwan, "Combined usage of micro-silica and nano-silica in concrete: SP demand, cementing efficiencies and synergistic effect", Constr. Build. Mater. Vol. 168, pp. 622-632, 2018.

[5]A. Hendi, H. Rahmani, D. Mostofinejad, A. Tavakolinia, and M. Khosravi, "Simultaneous effects of microsilica and nanosilica on self-consolidating concrete in a sulfuric acid medium", Constr. Build. Mater., 2017.

[6] S. Haruehansapong, T. Pulngem, and S. Chucheepsakul, "Effect of the particle size of nano silica on the compressive strength and the optimum replacement content of cement mortar containing nano-Sifr", Construction and Building Materials Vol. 50, pp. 471-277, 2014.

[7] F. Sanchez, and K. Sobolev, "Nanotechnology in concrete" - A review, Construction and Building Materials Vol. 24, pp. 2060-2071, 2010.

[8] L.P. Singh, S.R. Karade, S.K. Bhattacharyya, M.M. Yousuf, S. Ahalawat, "Beneficial role of nano silica in cement-based materials" - A review, Construction and Building Materials Vol. 47, pp. 1069-1077, 2013.

[9] N. Chahal, and R. Siddique, "Permeation properties of concrete made with fly ash and silica fume: Influence of ureolytic bacteria", Construction and Building Materials Vol. 49, pp. 161-174, 2013.

[10] H. Li, H.G. Xiao, J. Yuan, and J. Ou, "Microstructure of cement mortar with nano-particles", Composites: Part B Engineering Vol. 35, pp. 185-189, 2004.

[11] M. Berra, F. Carassiti, T. Mangialardi, A. E. Paolini, and M. Sebastiani, "Effects of nano silica addition on workability and compressive strength of Portland cement pastes", Construction and Building Materials Vol. 35, pp. 666 - 675, 2012.

[12] A. M. Mohamed, "Influence of nano materials on flexural behavior and compressive strength of concrete", HBRC J. Vol. 12, pp. 212-225, 2016.

[13] S. A. AI-Mishhamid, A.M. Ibraham and Z.H. Naji, "The effect of nano metakaolin materials on some properties of concrete", Diyala J. Eng. Sci. Vol. 6, pp. 50-61, 2013.

[14] G. Dhinakaran, A. Rajasekharareddy, B. Kartikeyan, K. Sumanth and G. Harshavardhan, "Microstructure analysis an strength properties of concrete with Nano SiO2", Int. J. Chem Tech. Res. Vol. 6, pp. 3004-3013, 2014.

[15] M. Gesoglu, E. Güneyisi, D. S. Asaad, and G. F. Muhyaddin, "Properties of low binder ultra-high-performance cementitious composites: comparison of nanosilica and 
microsilica", Construction and Building Materials Vol. 102, pp. 706-713, 2016.

[16] Egyptian standard specification of Cement (4756-1/2009).

[17] Standard Test Method for Compressive Strength of Hydraulic-Cement Mortars (ASTM C-109).

[18] TENSILE STRENGTH OF HYDRAULIC CEMENT MORTARS (ASTM C-190).

[19] Standard Test Method for Abrasion Resistance of Concrete by Sandblasting (ASTM C418-20).

[20] Standard Specification for Chemical Admixtures for Concrete (ASTM C-494).

[21] X. Chen, and S. Wu., "Influence of water-to-cement ratio and curing period on pore structure of cement mortar", Constr. Build. Mater. Vol. 38, pp. 804-812, 2013.

[22] V.G. Haach, G. Vasconcelos, and P.B. Lourenço, "Influence of aggregates grading and water/cement ratio in workability and hardened properties of mortars", Constr. Build. Mater. Vol. 25, No. 6, pp. 2980-2987, 2011.

[23] S. Mahdinia, H. Eskandari-Naddaf, and R. Shadnia, "Effect of cement strength class on the prediction of compressive strength of cement mortar using GEP method", Constr. Build. Mater. Vol. 198, pp. 27-41, 2019.

[24] G.A. Rao., "Development of strength with age of mortars containing silica fume", Cem. Concr. Res. Vol. 31, No. 8, pp. 1141-1146, 2001.

[25] S. Pandey, and R. Sharma, "The influence of mineral additives on the strength and porosity of OPC mortar", Cem. Concr. Res. Vol. 30, No. 1, pp. 19-23, 2000.

[26] A. Ghanei, H. Eskandari-Naddaf, and A. Davoodi, "Corrosion behavior and optimization of air-entrained reinforced concrete, incorporating microsilica", Struct. Concr. Vol. 19, No. 5, pp. 1472-1480, 2018.

[27] Y.K. Cho, S.H. Jung, and Y.C. Choi, "Effects of chemical composition of fly ash on compressive strength of fly ash cement mortar", Constr. Build. Mater. Vol. 204, pp. 255264, 2019.

[28] M. L. Nazargah, S.A. Emamian, E. Aghasizadeh, and M. Khani, "Predicting the mechanical properties of ordinary concrete and nano-silica concrete using micromechanical methods", Sadhana - Acad. Proc. Eng. Sci., 2018.

[29] N. Atmaca, M.L. Abbas, and A. Atmaca, "Effects of nanosilica on the gas permeability, durability and mechanical properties of high-strength lightweight concrete", Construction and Building Materials Vol. 147, pp. 17-26, 2017.

[30] D. HajizadehAsl, "Application of Nano-Silica in Concrete to Improve its Mechanical Properties and Durability: A Review", Int. J. Recent Sci. Res. Vol. 7, pp. 12251-12254, 2016.

[31] R. A. Narender and T. Meena, "Study on effect of colloidal Nano silica blended concrete under compression", Int. J. Eng. Technol. Vol. 7, pp. 210-213, 2018.

[32] R. A. Narender and T. Meena, "Behaviour of Ternary Blended Concrete under Compression", Int. J. Civil Eng. Technol. Vol. 8, pp. 2089-2097, 2017.

[33] R. A. Narender, and T. Meena, "A Comprehensive Overview on Performance of Nano Silica Concrete", Int. J. Pharm. Technol. Vol. 9, pp. 5518-5529, 2017.

[34] R. A. Narender and T. Meena, "An Experimental Investigation on Mechanical Behaviour of Eco-Friendly Concrete", Vol. 263, pp. 032010, 14th ICSET, 2017.

[35] R. A. Narender and T. Meena, "A Study on Compressive Behavior of Ternary Blended Concrete", Materials Today: Proceedings Vol. 5, pp. 11356-11363, 2018.

[36] L. K. Minapu, M.K.M.V. Ratnam, and U. Rangaraju, "Experimental Study on Light Weight Aggregate Concrete with Pumice Stone, Silica Fume and Fly Ash as a Partial Replacement of Coarse Aggregate", International Journal of Innovative Research in Science, Engineering and
Technology, (An ISO 3297: 2007 Certified Organization) Vol. 3, No. 12, December, 2014.

[37] K. Anusha and S. Kesavan, "A study on behavior of ultra-high strength concrete at elevated temperatures", International journal of engineering sciences \& Emerging technologies. ISSN: 22316604, Vol. 7, No. 5, pp. 761-765, Mar., 2015.

[38] T. Ji, "Preliminary study on the water permeability and microstructure of concrete incorporating nano-SiO2," Cement and Concrete Research Vol. 35, No. 10, pp. 1943-1947, 2005.

[39] S. Riahi, and A. Nazari, "Compressive strength and abrasion resistance of concrete containing $\mathrm{SiO} 2$ and $\mathrm{CuO}$ nanoparticles in different curing media," Science China Technological Sciences Vol. 54, No. 9, pp. 2349-2357, 2011.

[40] A. Nazari, and S. Riahi, "Abrasion resistance of concrete contain-ing SiO2and Al2O3nanoparticles in different curing media," Energy and Buildings Vol. 43, No, 10, pp. 29392946, 2011.

[41] F. Soleymani, "Abrasion resistance of concrete containing $\mathrm{SiO} 2$ nanoparticles in different curing Media," American Journal of Science Vol. 8, No. 8, pp. 171-178, 2012.

[42] H. Li, M.H. Zhang, and J.P. Ou, "Abrasion resistance of concrete containing nano-particles for pavement," Wear Vol. 260, No. 11-12, pp. 1262-1266, 2006. 